\title{
The Nature and Origins of Misperceptions: Understanding False and Unsupported Beliefs about Politics
}

\author{
D.J. Flynn \\ Pgm. in Quantitative Social Science \\ Dartmouth College \\ d.j.flynn@dartmouth.edu
}

\author{
Brendan Nyhan \\ Dept. of Government \\ Dartmouth College \\ nyhan@dartmouth.edu
}

\author{
Jason Reifler \\ Dept. of Politics \\ University of Exeter \\ j.reifler@exeter.ac.uk
}

\begin{abstract}
Political misperceptions can distort public debate and undermine people's ability to form meaningful opinions. Why do people often hold these false or unsupported beliefs and why is it sometimes so difficult to convince them otherwise? We argue that political misperceptions are typically rooted in directionally motivated reasoning, which limits the effectiveness of corrective information about controversial issues and political figures. We discuss factors known to affect the prevalence of directionally motivated reasoning and assess strategies for accurately measuring misperceptions in surveys. Finally, we address the normative implications of misperceptions for democracy and suggest important topics for future research.
\end{abstract}

This project has received funding from the European Research Council (ERC) under the European Union's Horizon 2020 research and innovation program (grant agreement No 682758). We thank Adam Berinsky, Daniel Diermeier, Jamie Druckman, Ben Page, Ethan Porter, Gaurav Sood, Joe Uscinski, attendees at the University of Michigan conference on How We Can Improve Health Science Communication, and especially the anonymous reviewers for useful suggestions and feedback. All remaining errors are of course our own. 
Scholars have long debated whether citizens are knowledgeable enough to participate meaningfully in politics. While standards of democratic competence vary (e.g., Lupia 2006; Druckman 2012), empirical research in public opinion yields a relatively simple answer to the question of how much people typically know about politics: not very much (e.g., Delli Carpini and Keeter 1996). However, the meaning and significance of citizens' inability to provide correct answers to factual survey questions can vary dramatically.

Most notably, as Kuklinski et al. (2000) point out, there is an important distinction between being uninformed (not having a belief about the correct answer to a factual question) and being misinformed (holding a false or unsupported belief about the answer). While scholars have long lamented public ignorance about politics, misperceptions (i.e., being misinformed) may be an even greater concern. In particular, misperceptions can distort people's opinions about some of the most consequential issues in politics, health, and medicine. Widespread evidence already exists of how misinformation has prevented human societies from recognizing environmental threats like climate change, embracing potentially valuable innovations such as genetically modified foods, and effectively countering disease epidemics like HIV/AIDS. In the United States, misperceptions have featured prominently in some of the most salient policy debates of recent decades.

Our goal in this article is to integrate the emerging literature on misperceptions into a more comprehensive theoretical framework. We first provide our preferred definition of misperceptions and document the evidence of their prevalence. Second, we argue that political misperceptions are typically rooted in directionally motivated reasoning, which is consistent with both observational and experimental evidence. As we note, however, there are significant theoretical and empirical 
gaps in our understanding of the mechanisms by which directional preferences affect factual beliefs and how that process varies across individuals and in different contexts. Third, we discuss the limitations of current approaches to measuring misperceptions in surveys and evaluate the strengths and weaknesses of possible alternatives. Fourth, we argue for devoting more attention to the role of elites and the media, who seem to play a critical role in creating and spreading misperceptions but have received relatively little scholarly attention to date. Finally, we discuss the normative significance of misperceptions for democratic politics.

\section{Defining misperceptions}

We begin by defining misperceptions as factual beliefs that are false or contradict the best available evidence in the public domain. ${ }^{1}$ These beliefs may originate internally (e.g., as a result of cognitive biases or mistaken inferences) or with external sources (e.g., media coverage). ${ }^{2}$ Critically, some misperceptions are demonstrably false (e.g., "weapons of mass destruction were discovered in Iraq after the U.S. invasion in 2003"), while others are unsubstantiated and unsupported by available evidence (e.g., "Saddam Hussein hid or destroyed weapons of mass destruction before the U.S. invasion in 2003"). Misperceptions differ from ignorance insofar as people often hold them with a high degree of certainty (Kuklinski et al. 2000; cf., Pasek, Sood, and Krosnick 2015) and consider themselves to be well-informed about the fact in question (Nyhan 2010; Polikoff 2015). ${ }^{3}$

Scholars who study false and unsupported beliefs have introduced a number

\footnotetext{
${ }^{1}$ Of course, the validity of factual claims is continuous, not binary. We restrict our focus to claims that are false or contradict the best available evidence in the public domain because they are especially normatively troubling.

${ }^{2}$ We discuss the causes of misperceptions and efforts to correct them below.

${ }^{3}$ We discuss measurement strategies for distinguishing misperceptions from ignorance below.
} 
of related terms, such as interpretations, rumors, and conspiracy theories. It is useful to clarify at the outset how our definition relates to each of these terms. For instance, Gaines et al. (2007) discuss the "interpretation" of various facts related to the Iraq War. One such fact is the U.S. military's failure to discover weapons of mass destruction (WMD) after the 2003 invasion of Iraq. While most respondents believe correctly that WMD were not found, Democrats and Republicans interpreted this fact differently: Democrats inferred that Saddam Hussein did not possess WMD immediately before the invasion, while Republicans inferred that the weapons had been moved, destroyed, or had not yet been discovered (Gaines et al. 2007, 962-965). The latter interpretation is inconsistent with the best available evidence and we therefore define it as a misperception (e.g., Duelfer 2004).

Rumors and conspiracy theories are two related terms for claims that fail to meet widely agreed upon standards of evidence. DiFonzo and Bordia (2006, 13) define rumors as "unverified and instrumentally relevant information statements in circulation that arise in contexts of ambiguity, danger, or potential threat and that function to help people make sense [of] and manage risk." One of the most distinctive feature of rumors is rapid social transmission (DiFonzo and Bordia 2006; Berinsky 2015). For example, rumors about Ebola circulated widely in West Africa during the 2014 outbreak (Gidda 2014). Conspiracy theories, on the other hand, refer to claims that seek "to explain some event or practice by reference to the machinations of powerful people, who attempt to conceal their role" (Sunstein and Vermeule 2009, 205). They are distinctive insofar as they focus on the behavior of powerful people and may be rooted in stable psychological predispositions (Uscinski and Parent 2014; Uscinski, Klofstad, and Atkinson 2016). A prominent example of a conspiracy theory in contemporary American politics is the belief that the 
September 11 attacks were an "inside job" aided or carried out by the government.

When interpretations, rumors, and conspiracy theories like these are false or unsupported by the best available evidence, they can be usefully defined and analyzed as misperceptions (though there are, of course, important differences between the concepts). ${ }^{4}$ In particular, we argue that directional motivated reasoning is a useful framework for understanding each of these types of misperceptions.

\section{The prevalence and persistence of misperceptions}

By the definition provided above, misperceptions appear to be widespread (e.g., Ramsay et al. 2010) on issues ranging from the economy (e.g., Bartels 2002) to foreign policy (e.g., Kull, Ramsay, and Lewis 2003). For instance, Flynn (2016) found that more than one in five Americans confidently holds misperceptions about the largest holder of the U.S. debt, universal background checks, changes in debt and deficits, the federal tax burden, and time limits on welfare benefits. ${ }^{5}$

Misperceptions are prevalent in a number of ongoing debates in politics, health, and science. In the recurring debate over gun control, for example, many citizens falsely believe that universal background checks are already mandated under existing law (Aronow and Miller 2016). Similarly, a substantial number of Americans reject widespread evidence that earth's climate is warming (McCright and Dunlap 2011); erroneously believe that some vaccines cause autism in healthy children (Freed et al. 2010); and endorse misperceptions about the dangers of genetically modified foods that contradict the scientific consensus that they are safe to consume (Entine 2015). In some cases, misperceptions extend to the powers of political

\footnotetext{
${ }^{4}$ Important caveat: Rumors and conspiracy theories can turn out to be true!

${ }^{5}$ Earlier surveys of beliefs about U.S. debt holders (Thorson 2015b), gun background checks (Aronow and Miller 2016), and welfare benefits (Thorson 2015b) reached similar conclusions.
} 
offices and institutions. For instance, Democrats claimed George W. Bush could have reduced gas prices despite the president's lack of power over them, but were much less likely to state that Barack Obama could do so (while Republicans shifted in the opposite direction, though to a lesser extent; see Weiner and Clement 2012).

Perhaps more troubling, misperceptions often continue to influence policy debates after they have been debunked. For instance, Nyhan (2010) documents the role misinformation played in the 1993-1994 and 2009-2010 health reform debates. Opponents of the 1993-1994 reform claimed that the plan would prohibit patients from continuing to see their preferred doctor and prevent them from purchasing coverage outside the proposed system of managed competition. In 2009-2010, opponents claimed that the proposed plan would establish "death panels" that would deny costly care to individual patients. Both these claims were widely debunked, but as Nyhan $(2010,4)$ explains, they "distorted the national debate, misled millions of Americans, and damaged the standing of both proposals before Congress." The death panel misperception, which persists today (Nyhan 2014), delayed Medicare coverage of voluntary end-of-life consultations with doctors for years. After the misperception became widespread, the provision was removed from the Affordable Care Act. It was then proposed as a Medicare rule after the bill's passage, but dropped again due to further controversy in 2011 (Leonard 2015). ${ }^{6}$

Because studies in this field have typically been conducted in the United States, one might be tempted to believe that misperceptions are a uniquely American problem. They are not. For instance, as Figure 1 shows, Europeans greatly overestimate the number of foreign-born residents in their countries. Misperceptions like these are associated with anti-immigrant attitudes and policy preferences in

\footnotetext{
${ }^{6}$ The provision was finally adopted via a Medicare rule change in 2015 (Pear 2015).
} 
Figure 1: European misperceptions of foreign-born populations

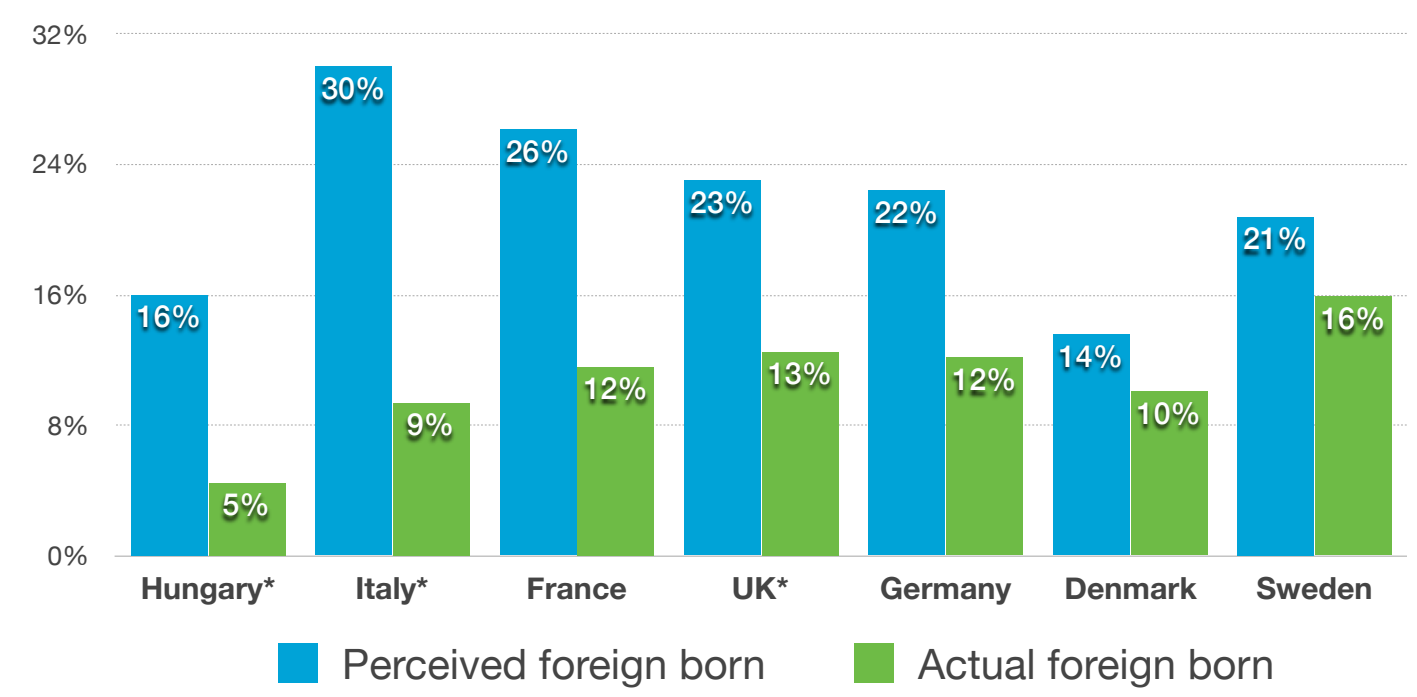

Survey data from ESS (2014) and Ipsos MORI* (2013). Foreign-born population data from Eurostat (2014 data).

Europe (Sides and Citrin 2007, 491-492), though this relationship has not been observed in the United States (Hopkins, Sides, and Citrin N.d.). More recently, U.K. citizens were widely misinformed about several facts related to the debate over the U.K.'s possible departure from the European Union ("Brexit"), including the size of the immigrant population, U.K. payments to and receipts from the EU, EU administrative costs, and others (Ipsos MORI 2016). Misperceptions may also promote extremism and intergroup conflict in regions such as the Middle East (Gentzkow and Shapiro 2004).

\section{The effects of misperceptions and corrective information}

How do these mistaken factual beliefs affect public opinion? Hochschild and Einstein (2015) provide a useful typology for understanding the possible effects of misperceptions. They discuss four sorts of factual beliefs which vary along two 
dimensions: whether they are correct or incorrect and whether they are associated with distinct political choices or actions. The result is a four-category typology, which consists of the active informed, inactive informed, active misinformed, and inactive misinformed. Of particular concern are the active misinformed: people who "hold incorrect 'knowledge' that is associated with distinctive involvement with the public arena" (11). These are people whose opinions and behavior are different from what we might observe if they held accurate beliefs. Correcting misperceptions could thus alter their political views or behavior.

Unfortunately, research indicates that corrective information often fails to change the false or unsupported belief in question, especially when the targeted misperception is highly salient. ${ }^{7}$ In some cases, corrections can make misperceptions worse (Nyhan and Reifler 2010; Nyhan, Reifler, and Ubel 2013). Even the release of President Obama's long-form birth certificate had only a brief effect on beliefs that he was not born in this country (Nyhan 2012). Moreover, people have difficulty accurately updating their beliefs after finding out that information they previously accepted has been discredited (Bullock 2007; Cobb, Nyhan, and Reifler 2013; Thorson 2015a). Other research shows that reminders of social difference or cues about outgroup membership may also reduce the effectiveness of corrections (Garrett, Nisbet, and Lynch 2013). Empirical claims do not appear to be strengthened when delivered under oath (Nyhan 2011). Similarly, affirming a truth is not necessarily more effective than denying a false claim (Nyhan and Reifler 2013). These findings help explain why belief in the most significant misperceptions is often quite stable over time (Nyhan 2012).

\footnotetext{
${ }^{7}$ The studies cited below almost exclusively consider lab and survey experiments. Results might of course differ if these studies were conducted as field experiments - an important consideration for future research (Jerit, Barabas, and Clifford 2013).
} 
However, there is room for guarded optimism, as other approaches have proved more effective at addressing misperceptions. For example, corrective information may be more persuasive to skeptical groups when it originates from ideologically sympathetic sources (Berinsky 2015) or is presented in graphical rather than textual form (Nyhan and Reifler N.d.b). In addition, providing an alternate causal account for events has been found to be more effective than simply refuting an unsupported claim (Nyhan and Reifler 2015a). Corrections from professional factcheckers have also been shown to reduce misperceptions (e.g., Fridkin, Kenney, and Wintersieck 2015), though their effectiveness may vary based on the public profile of the target politician and the salience of the claim in question. A related study by Bode and Vraga (2015) finds that exposure to disconfirming "related stories" on Facebook may also help limit the spread of misperceptions.

Results are similarly mixed when we consider the effects of corrective information on related policy opinions. Though some studies show facts can affect opinions on issues like education spending (Howell and West 2009) and the estate tax (Sides 2016), others find that correct information does not affect opinions on highly salient policy issues. For example, Kuklinski et al. (2000) find that providing respondents with extensive factual information about welfare and health care did not alter support on either issue; Berinsky (2009) shows that giving people several types of factual information about the Iraq War (e.g., casualties and costs) failed to affect their opinions about the wisdom of the war; and Hopkins, Sides, and Citrin (N.d.) show that correcting misperceptions about the size of immigrant populations does not increase support for immigration. These results suggest that political misperceptions may sometimes be a consequence of directional preferences 
rather than a cause of issue or candidate opinions. ${ }^{8}$

Finally, misperceptions can continue to affect opinions even after being successfully corrected. Early research on non-political topics showed remarkable evidence of "belief perseverance" or "a continued influence effect" after initial information given to respondents was definitely debunked (e.g., Ross, Lepper, and Hubbard 1975; Wilkes and Leatherbarrow 1988). Recent studies show that these effects extend to politics: Bullock (2007), Nyhan and Reifler (2015a), and Thorson (2015a) all find lingering effects of smears and bogus claims on opinions of political figures and issues after they have been discredited. ${ }^{9}$ These effects can be exacerbated by directional preferences. Bullock (2007) and Thorson (2015a) find that the continued influence of false information is in some cases greater among opposition partisans.

\section{Directionally motivated reasoning about facts}

The most useful framework for understanding misperceptions about politics comes from psychological research on motivated reasoning. In this section, we review what is known about directionally motivated reasoning, how its strength versus accuracy motivations might vary across contexts, and consider the mechanisms by

\footnotetext{
${ }^{8}$ The question of whether misperceptions affect opinions or vice versa resists easy generalization. We discuss this issue further below, but note that misperceptions can have important consequences for policy debate and public attitudes even if correcting them does not change people's opinions.

${ }^{9}$ Cobb, Nyhan, and Reifler (2013) observe an interesting asymmetry in testing for perseverance effects on positive misinformation. While debunked negative information leaves lingering negative effects, they find that debunked positive information prompts an overcorrection in which people actually view the politician in question more negatively.
} 
it might operate. ${ }^{10}$

It is useful to begin by reviewing the psychology of directionally motivated reasoning. As Kunda (1990) explains, when people process information, different goals may be activated, including directional goals (trying to reach a desired conclusion) and accuracy goals (trying to process information as dispassionately as possible). In the context of political misperceptions, the term "motivated reasoning" typically refers to directionally motivated reasoning, which is, arguably, the most common way that people process political stimuli (Redlawsk 2002; Taber and Lodge 2006). ${ }^{11}$ Directionally motivated reasoning leads people to seek out information that reinforces their preferences (i.e., confirmation bias), counter-argue information that contradicts their preferences (i.e., disconfirmation bias), and view pro-attitudinal information as more convincing than counter-attitudinal information (i.e., prior attitude effect) (Taber and Lodge 2006, 757).

Two of the most common sources of directional motivated reasoning are partisanship (Bolsen, Druckman, and Cook 2014) and prior issue opinions (Taber and Lodge 2006; also see Mullinix 2016). ${ }^{12}$ Nonetheless, isolating the mechanisms underlying directional motivated reasoning poses a serious challenge (see below as well as Bullock, Green, and Ha 2010). Fortunately, directional motivated reasoning has numerous observable implications. First, it may lead to selective exposure, which occurs when people's directional preferences influence their infor-

\footnotetext{
${ }^{10}$ Of course, other theoretical approaches can provide useful insights. For instance, people may form false beliefs by making incorrect inferences from available information (Prasad et al. 2009; Thorson 2015b) - a process that is often shaped by cognitive biases (Arceneaux 2012; Petersen 2015).

${ }^{11}$ Using the term "motivated reasoning" to describe directionally motivated reasoning is thus a slight oversimplification: all information processing is motivated is some sense.

${ }^{12}$ Other directional motivations are of course possible, including impression or behavioral motivations (Kunda 1990). We focus on partisanship and issue opinions because they are most relevant to the political context.
} 
mation consumption choices. For example, Democrats and Republicans exhibit markedly different preferences for cable news programming (e.g., MSNBC vs. Fox; Stroud 2008). ${ }^{13}$ Second, people may engage in motivated processing of the information they receive. More specifically, studies show we tend to accept and recall congenial factual information more frequently than uncongenial facts (Jerit and Barabas 2012; Kahan, Dawson, Peters, and Slovic N.d.); interpret facts in a beliefconsistent manner (Gaines et al. 2007); rationalize to maintain consistency with other beliefs they hold (Lauderdale 2016); and counter-argue corrective information (Nyhan and Reifler 2010). Finally, directional motivations may exacerbate the continued influence of false information even after it has been debunked (Bullock 2007; Thorson 2015a).

Isolating the effects of directional motivations is difficult because it requires a comparison to an unobserved counterfactual in which information processing occurred with accuracy or some other goal in mind. For instance, different beliefs about an event between Democrats and Republicans could reflect directional motivations, but could also be attributable to different types of information exposure, different priors, etc. The cleanest approach to estimating the influence of directional motivations on information processing comes from what Kahan, Dawson, Peters, and Slovic (N.d.) call the "Politically Motivated Reasoning Paradigm," which isolates how people view the same evidence depending on its consistency with their directional preferences. A recent experiment by Kahan (2015b) using this approach helps show clearly just how powerfully directional motivations can shape information processing. In the experiment, participants were randomly

\footnotetext{
${ }^{13}$ However, observational data from the real world suggest that the extent of selective exposure is more limited than many assume (Gentzkow and Shapiro 2011; Bakshy, Messing, and Adamic 2015; Barberá et al. 2015; Flaxman, Goel, and Rao 2016; Guess N.d.).
} 
assigned to receive a table of outcome data that was labeled as either showing how a skin cream affects a rash or how gun control affects crime. The success of the intervention (i.e., skin cream, gun control) was also randomly varied between respondents. When the table was presented as data about whether a skin cream helped a rash or not, there were no major differences in how people of different ideological leanings interpreted the data. But when the data were instead presented as evidence about the effectiveness of gun control, people's interpretation of the results became polarized by ideology. Similarly, Schaffner and Roche (N.d.) find that Democrats and Republicans reacted very differently to news that the unemployment rate fell below $8 \%$ in fall 2012. Democrats typically revised their estimates of unemployment downward, whereas many Republicans appeared to counter-argue the news, revising their estimates upwards instead. In sum, these studies show that people's interpretation of factual information depends on whether the information reinforces or contradicts directional preferences.

In politics, directional processes like these are often theorized to be rooted in affect. According to the John Q. Public Model of information processing (Lodge and Taber 2013, ch. 2), for instance, most political objects (e.g., candidates, issues) are affect-laden, and people update beliefs towards objects using their existing affective evaluations. When confronted with stimuli, affective reactions occur prior to conscious awareness. For instance, evaluations of Barack Obama are shaped by one's initial, instantaneous affective reaction towards Obama. This general reaction then activates a series of related considerations in long-term memory, such as Obama's partisanship, ideology, personality, and (perhaps) Obama-relevant misperceptions. In this sense, affect could serve as as a mechanism of directionally motivated reasoning and thereby fuel misperceptions. This process may be espe- 
cially driven by negative affect toward out-party policies and figures (Roush N.d.), who are often the target of misperceptions. ${ }^{14}$

Another factor that may promote directionally motivated reasoning is identity threat. Political facts often implicate long-standing, personally important identities such as partisanship (Green, Palmquist, and Schickler 2004; Steele 1988). If these facts are perceived as sufficiently threatening to one's identity or worldview, people may seek to resist them. ${ }^{15}$ People may also feel social pressure to think and act in ways that are consistent with important group identities (Sinclair 2012; Kahan, Jamieson, Landrum, and Winneg N.d.). We know that humans are heavily influenced by their peers and social contacts (e.g., Gerber, Green, and Larimer 2008; Gerber and Rogers 2009; Paluck 2011; Meer 2011; Bollinger and Gillingham 2012; Bond et al. 2012; Kast, Meier, and Pomeranz 2012; Paluck and Shepherd 2012). Under these conditions, the motivation driving reasoning could be expressly directional: reasoning (perhaps unconsciously) toward conclusions that reinforce existing loyalties rather than conclusions that objective observers might deem "correct."

An alternative to directional motivations are accuracy motivations. People driven by accuracy goals collect and analyze available information with the goal of forming accurate factual beliefs, rather than beliefs that reinforce directional preferences. Reasoning motivated by accuracy goals may involve greater cognitive

\footnotetext{
${ }^{14} \mathrm{An}$ interesting alternative model of emotion's role in motivated reasoning is provided by Redlawsk, Civettini, and Emmerson (2010), who suggest that respondents who repeatedly encounter disconfirming information in politics may reach an "affective tipping point" at which they become increasingly anxious and willing to reconsider their views. More research is needed to investigate the conditions under which anxiety motivates open-mindedness (see, e.g., Marcus, Neuman, and MacKuen 2000 versus Ladd and Lenz 2008, 2011).

${ }^{15}$ An implication of this model is that affirming people's self-worth in some other domain may reduce the extent to which people engage in worldview defense (e.g., Cohen, Aronson, and Steele 2000; Correll and Spencer 2004). However, Nyhan and Reifler (N.d.b) found suggestive but only partial empirical support for this conjecture.
} 
elaboration, as people consider all available evidence in order to form accurate beliefs (Kunda 1990, 481; but see Kahan, Dawson, Peters, and Slovic N.d.). Results from experimental studies suggest that inducements to form an accurate opinion can reduce or eliminate the effects of directional motivations (e.g., Bolsen, Druckman, and Cook 2014; cf., Taber and Lodge 2006). ${ }^{16}$

\section{Directional versus accuracy motivations}

To reiterate, accuracy and directional motivations affect how people search for, evaluate, and incorporate information into their beliefs. As discussed above, when people are motivated by directional goals, information acquisition and processing are driven by the desire to reach or reinforce a specific conclusion. ${ }^{17}$ By contrast, when people are motivated by accuracy goals, they search for and evaluate evidence in an even-handed manner in order to form a belief that reflects the true state of the world. It is important to note, however, that when people are motivated by directional goals, accuracy primes delivered in experiments or surveys still generally result in observable behavior consistent with accuracy goals (Redlawsk 2002; Bolsen, Druckman, and Cook 2014; Bolsen and Druckman 2015; see also Druckman 2012).

These results have two key implications. First, directional goals are the default in processing information at the individual level. Second, tendencies toward accuracy or directionally motivated processing are not immutable. The relative strength of directional and accuracy motivations can vary substantially between individuals and across contexts. The pressing question, then, becomes which con-

\footnotetext{
${ }^{16}$ We consider other ways to promote accuracy motivations below.

${ }^{17}$ Directional motivations may be unconscious; studies such as Taber and Lodge (2006) and Berinsky (N.d.) find evidence of persistent motivated reasoning even when participants are explicitly instructed to be evenhanded or to set aside their political preferences.
} 
textual and individual level factors influence the tug-of-war between accuracy and directional motivations. We elaborate below with a pair of non-political examples.

In some contexts, we would expect accuracy goals to be particularly strong relative to directional goals. For example, when purchasing home appliances, people have relatively weak directional preferences; they likely want to learn which refrigerator is most convenient or efficient or which dishwasher best washes and dries dishes. We would thus expect people to be relatively even-handed in their search for information and in how they evaluate the information they encounter. However, it is still possible to envision how how directional goals could affect even mundane choices like these. Some people may have particularly strong brand preferences, which could influence their information search and evaluation process. More subtly, people may have (unacknowledged) preferences for lavish or frugal consumption that affects whether people interpret the evidence as supporting purchasing a more or less expensive brand or model. While accuracy goals are dominant, there may still key individual variation in how these types of directional goals may creep in. Similarly, contextual factors may affect the strength of directional cues by, for instance, varying the salience of brand preferences. ${ }^{18}$

Contextual and individual differences can also affect the relative strength of accuracy and directional motivations in situations where we expect directional motivations to be relatively stronger. Sports fandom provides a useful non-political analogy. An ardent supporter of a team likely employs different standards of what counts as a foul or infraction depending on whether her team or the opposing team was responsible. Perceptions of what occurs on the field are heavily influenced by

\footnotetext{
${ }^{18}$ We of course acknowledge that brands are not uninformative; they may convey some reputational information about product reliability or quality. The discussion here is intended to focus on how brand preferences could produce directional biases in information processing to reinforce some preferred outcome (e.g., buying a Sub-Zero refrigerator).
} 
what the fan would like to happen (e.g., Hastorf and Cantril 1954). Nonetheless, we should still expect there to be both individual- and contextual-level differences in the relative balance of motivations. At the contextual level, the environment in which the fan watches the game (e.g., a home or away stadium, sports bar, friend's house, etc.) and with whom she watches the game (e.g., fellow fans, fans of the opposing team, etc.) may influence the balance between accuracy and directional motivations and thus how fans perceive the game. At the same time, we should also expect individual-level differences in accuracy versus directional motivations depending on factors such as the extent to which fans identify with their preferred team.

According to this line of thinking, affectively-charged contexts like a game or match involving a preferred sports team should enhance directional goals, whereas less affect-laden contexts like shopping for home appliances should favor accuracy goals. This account is broadly consistent with the observation that the most prominent misperceptions often concern some of the most controversial (and therefore affect-laden) policy issues (e.g., the Affordable Care Act) and political figures (e.g., President Obama) in American politics. These hot-button issues also appear to be where we are most likely to observe backfire effects (Redlawsk 2002; Gollust, Lantz, and Ubel 2009; Nyhan and Reifler 2010; Nyhan, Reifler, and Ubel 2013; Schaffner and Roche N.d.). By contrast, studies conducted on other issues that often feature less well-known misperceptions and more one-sided information treatments have typically not observed backfire effects (e.g., Weeks 2015; Nyhan and Reifler N.d.a; Wood and Porter N.d.; Hill N.d.; Kim N.d.), suggesting that highly polarized responses and backfire effects may be more likely for highly salient misperceptions 
when people receive conflicting cues. ${ }^{19}$ Yet Redlawsk (2002), Bolsen, Druckman, and Cook (2014), and Bolsen and Druckman (2015) find that under certain conditions accuracy motivations can weaken directional goals. Understanding when (and why) directional and accuracy goals take precedence over one another is a critically important avenue for future research.

These differing findings raise crucial questions about proper facts to consider in studying misperceptions. Numerous facts could be politicized. However, most are not. It is not surprising that studies of beliefs about non-politicized facts will therefore tend to show greater responsiveness to new or corrective information (especially on matters that are difficult to counter-argue, such as the true value of relatively obscure statistics) than those that focus on the much smaller set of high-profile misperceptions. Both types of beliefs are relevant to understanding how people reason about facts. It is important to recognize how the set of beliefs considered affects the conclusions that we draw.

\section{Moderators of directionally motivated reasoning}

Given the importance of directionally motivated reasoning, understanding the individual- and contextual-level moderators that diminish or exacerbate directionally motivated responses to political information and integrating these into a theoretical model is vital. We analyze several of the most important moderators identified in previous research below.

\footnotetext{
${ }^{19}$ See also Guess and Coppock (N.d.) for a similar set of results on the effects of information on issue opinions.
} 


\section{Contextual moderators}

We first consider several important contextual moderators of directional motivated reasoning - that is, factors known to promote or attenuate the influence of directional goals in information processing. ${ }^{20}$

One important factor is polarization among party elites, which increases the salience of partisan motivations when evaluating information. Druckman, Peterson, and Slothuus (2013) conducted two experiments to investigate the moderating role of elite partisan polarization on opinion formation towards immigration and drilling for oil and gas. Specifically, they exposed people to arguments for or against each policy proposal and randomized the degree of elite polarization on the issue: some participants read that Democrats and Republicans were both united but on opposite sides of the issue (i.e., high polarization), while others read that members of either party could be found on both sides of the issue (i.e., low polarization). The authors find that polarization causes people to shift their opinions in the direction of co-partisan elites regardless of the types of arguments they read. These results suggest that elite polarization increases the importance of directional (partisan) motivations in opinion formation. Similarly, Levendusky (2010) provides experimental evidence that elite polarization increases citizens' reliance on partisan cues (a directional motivation) in the opinion formation process across five issues.

Partisan polarization effects like these may be exacerbated by source effects. In-group members are, for instance, more likely to be perceived as holding common interests (Lupia and McCubbins 1998) and to be viewed warmly (Iyengar, Sood, and Lelkes 2012). Political arguments that are attributed to in-group sources are thus generally more persuasive than messages from outgroups (O'Keefe 2002). For

\footnotetext{
${ }^{20}$ This list is of course not exhaustive, but hope it aids the field in developing a more systematic understanding of the conditions under which directional and accuracy goals are strongest.
} 
example, Slothuus and de Vreese (2010, 636-637) show that the effectiveness of frames regarding welfare and trade policy depends on the party to which the frames are attributed; specifically, participants are more persuaded by frames from their own party than by identical frames from the opposing party (also see Kam 2005; cf., Bullock 2011). Petersen et al. (2013, 841-842) provide direct evidence that partisan cues affect the extent to which people engage in effortful processing of political arguments. They show that participants who disagreed with their party's position took longer to consider the argument and form opinions than participants who agreed with their party's position, suggesting that disagreeing with one's party requires additional cognitive effort. ${ }^{21}$

Conversely, messages from in-group members or those providing evidence of consensus can be powerful factors in counteracting directional biases on politically charged issues. For instance, Nyhan and Reifler (2013) and Berinsky (2015) provide some evidence that corrective information from elites and media outlets who share a respondent's ideology or partisanship might be more effective than other sources. Similarly, Bolsen and Druckman (2015) and Lewandowsky, Gignac, and Vaughan (2013) find that informing people about a scientific consensus can reduce directionally motivated reasoning, though other scholars question the effectiveness of this approach, most notably on climate change (e.g., Kahan 2015a).

An additional factor in the prevalence of directional motivated reasoning is salience. Specifically, directional motivations are likely to be stronger for highly salient political disputes and issues and when considering prominent and controversial political figures. Jerit and Barabas (2012), for instance, document how issue

\footnotetext{
${ }^{21}$ Even this study provides only indirect evidence of counter-arguing or other mechanisms of effortful resistance to unwelcome information. Future research should seek to test presumed mechanisms directly when possible, though establishing the mediators of any such effect is extremely difficult (Bullock, Green, and Ha 2010).
} 
salience affects the degree of partisan perceptual bias in learning political facts from media coverage. People are not only more likely to correctly answer survey questions about facts that reflect positively on their party, but this bias is exacerbated on issues that received high levels of media coverage (Jerit and Barabas 2012, 675-679). Variations in issue salience may also help explain the differing levels of resistance to corrective information found in the studies described above - people's willingness to engage in effortful resistance may vary depending on whether the issue is well-known and salient.

\section{Individual-level moderators}

In addition to the contextual factors discussed above, individual-level factors also affect the balance between accuracy and directional goals. We examine several important individual-level factors associated with directional motivations below.

One of the most important moderators of directionally motivated reasoning is sophistication, including both political knowledge and education. Directionally motivated reasoning occurs most often with people who have relatively high levels of political knowledge (Taber and Lodge 2006). Nyhan, Reifler, and Ubel (2013) find that attempts to correct the "death panel" misperception backfire among respondents who feel very warmly towards Sarah Palin and who have high levels of political knowledge. Similarly, people with higher levels of knowledge may be better able to resist incongruent information and maintain alignment between their factual beliefs and predispositions (e.g., Nyhan and Reifler 2012; Taber and Lodge 2006). For instance, in the skin cream/gun control study described above, Kahan (2015b) find that polarization in interpretation of outcome data was greatest among the most numerate people. 
These studies capture two possible mechanisms by which sophistication and education can lead to motivated reasoning: greater recognition of "what goes with what" (Converse 1964) and greater ability to counter-argue incongruent information (e.g., Nyhan and Reifler 2010). These mechanisms have important implications for our understanding of directionally motivated reasoning more generally. In particular, they suggest that directional motivated reasoning can operate via either systematic, effortful information processing (e.g., Kahan, Landrum, Carpenter, Helft, and Jamieson N.d.) or via heuristic, low-effort information processing (e.g., Lodge and Taber 2013). For instance, recognizing the significance of a given fact for one's directional preferences may lead people to quickly dismiss (accept) incongruent (congruent) information - a form of heuristic processing. On the other hand, using expertise to counter-argue incongruent messages requires greater cognitive effort, which is associated with systematic information processing (see Petersen et al. 2013). The use of heuristic versus systematic directional motivated reasoning is no doubt conditional. We point out both possibilities because it informs our consideration of motivated reasoning below.

More controversially, some have argued that ideology may affect the extent to which people engage in directionally motivated reasoning. Jost et al. (2003) and others have argued that political conservatism is associated with a tendency toward directionally motivated reasoning because its modest correlations with other constructs that might influence the relative strength of directional and accuracy goals. For example, political conservatives typically score lower on items assessing openness to experience on personality or values inventories. Instances of backfire effects - where corrections result in a strengthening of political misperceptionshave been observed among conservatives (Nyhan and Reifler 2010; Nyhan, Reifler, 
and Ubel 2013). However, the broader set of evidence suggests that directionally motivated reasoning is common among all humans. Much more evidence would be required to support the claim that particular ideological groups are more prone to directional reasoning because of their ideology. ${ }^{22}$ For instance, it would be helpful construct and validate a scale (or scales) that measures individual-level differences in the strength of underlying accuracy and/or directional motivations.

Third, certain psychological factors may attenuate the strength of directional motivated reasoning. Here we note three factors identified in recent research. First, Groenendyk (2013) argues that people are motivated to appear as "good citizens" who dispassionately evaluate information in the interest of forming accurate opinions. When such civic-minded motivations are primed, directional motivations become less salient, making people more willing to adjust important attitudes (including partisan identification!) in response to new information. Second, as Lavine, Johnston, and Steenbergen (2012) explain, partisans who are ambivalent - meaning they disagree with their party on one or more important issues - are less likely to engage in directional motivated reasoning. In addition, Kahan, Landrum, Carpenter, Helft, and Jamieson (N.d.) show that participants who are high in science curiosity are more willing to consider scientific information that contradicts their preferences on politicized scientific issues like climate change.

Fourth, social category differences may contribute to directionally motivated misperceptions. For instance, Garrett, Nisbet, and Lynch (2013) find that presenting people with background information that they find culturally objectionable reduces the effectiveness of subsequent corrections. Similarly, Kosloff et al.

\footnotetext{
${ }^{22}$ One of many inferential concerns that could be noted is that liberals and conservatives differ on many relevant non-psychological dimensions, including the structure of their affiliated parties and media outlets — see, e.g., Grossmann and Hopkins (2016).
} 
(2010) find that reminding people of differences in racial identity or age from the presidential candidates in the 2008 election increased smear acceptance. These factors may have helped fuel widespread misperceptions about Barack Obama, such as the belief that he is Muslim or foreign-born, which are closely associated with measures of ethnocentrism and racial resentment among whites (e.g., Kam and Kinder 2012).

\section{Measuring factual (mis)perceptions}

There is an important ongoing debate about best practices for measuring misperceptions in surveys. Much of the debate focuses on whether incorrect answers to factual survey questions are evidence of misperceptions. Questions like these represent fundamental epistemological concerns in survey research — are we capturing citizens' genuine beliefs and attitudes or artifacts of the survey response process? In this section, we consider existing research on measuring factual beliefs in surveys and assess the strengths and weaknesses of different approaches.

Studies that examine factual beliefs typically rely on survey questions that ask respondents to evaluate a statement or claim using some form of a Likert scale. For instance, respondents in a survey may be asked whether they agree or disagree with a statement such as "The murder rate in the United States is the highest it's been in 45 years," a claim made by Donald Trump during the 2016 presidential campaign (Lopez 2016b). Because the claim is false (Federal Bureau of Investigation 2015), the most accurate response is to disagree. But what does it mean if a person agrees with the statement? Answering "agree" may mean that

the subject fully endorses the claim that the murder rate in the United States is at its highest point in the past 45 years. However, "agree" could also be a way for 
a respondent to reveal a belief that crime is higher today than at some point in the past or simply a purely expressive response signaling support for Trump. The latter explanation - that respondents are using their response to signal support for Donald Trump - is a form of expressive responding. ${ }^{23}$ If expressive responding is common, then traditional closed-end survey questions likely overstate the extent and strength of people's belief in misperceptions.

Two recent studies have sought to assess the prevalence of expressive responding in people's answers to factual survey questions. Specifically, Bullock et al. (2015) and Prior, Sood, and Khanna (2015) increase the cost of expressive responding by offered monetary incentives for correct answers. Both studies find that incentives reduce partisan polarization in measured factual beliefs. However, these studies do not clearly indicate that people intentionally suppress more accurate beliefs in favor of partisan cheerleading. If this account were correct, we would expect respondents to report more accurate beliefs when incentives were offered. Instead, the studies find only partial and inconsistent evidence of greater belief accuracy as a result of incentives. Providing incentives may at least in part cause people to answer in a more thoughtful or considered manner-Bullock et al., for instance, find more "don't know" responses as a result of incentives in their second study - or to use different heuristics that reduce the influence of directional motives without generally increasing accuracy. ${ }^{24}$ In that sense, these studies offer an important reminder that the relative strength of directional and accuracy motivations can vary dramatically depending on the context and incentives people face.

\footnotetext{
${ }^{23}$ This is synonymous with partisan "cheerleading" (e.g., Gerber and Huber 2009).

${ }^{24} \mathrm{An}$ alternate possibility is that polarization is reduced because respondents seek to provide answers that scholars would define as correct in order to be paid more. If this conjecture were true, what seems to be a reduction in expressive responding could instead reflect response bias induced by the incentives provided by researchers.
} 
Importantly, the fact that people answer in a less partisan way when accuracy incentives are high does not mean their answers under normal circumstances (when accuracy incentives are lower) are not reflective of their "true" belief - a concept that is ill-defined in the context of public opinion. Though some passages in Bullock et al. (2015) suggest that people are choosing whether or not to report some belief they do not believe to be accurate, we contend that survey respondents are constructing responses to most factual survey questions from the top of their head. As on opinion surveys (e.g., Zaller 1992), survey respondents who are asked a factual question must draw upon a set of considerations from memory and the question and construct an answer. ${ }^{25}$ Though respondents likely have existing considerations to draw upon in answering questions about the most salient misperceptions, the responses that researchers receive will still change when the context of the question or the incentives facing the respondent change. This variation may be especially acute when the questions are difficult. For instance, many of the factual questions asked by Bullock et al. (2015) concern obscure quantitative values that almost no respondent could possibly answer from memory (e.g., the proportion of federal spending devoted to the military). As a result, few people have existing beliefs of any kind that they can either honestly report or misrepresent. Accordingly, their answers may be more sensitive to incentives, question format, etc. than questions probing other beliefs that people hold more strongly.

In addition to monetary incentives, another approach to evaluating expressive responding is list experiments (Kuklinski, Cobb, and Gilens 1997), a framework that might reduce the incentive to engage in an expressive response and thereby reveal the proportion of respondents who are reporting their beliefs sincerely. Un-

\footnotetext{
${ }^{25}$ Of course, one could imagine that such a process could itself be expressive.
} 
fortunately, list experiments have low statistical power and are highly sensitive to design quirks and respondent compliance (see Kramon and Weghorst 2012 for a review). As a result, numerous researchers report problems with using them in practice (Gelman 2014). Moreover, list experiments work best when the presumed misreporting effect is unidirectional. With misperceptions, however, some respondents may overreport misperceptions as a form of partisan cheerleading and others could underreport due to social desirability concerns, creating offsetting effects that a list experiment cannot easily disentangle.

The account provided above is consistent with evidence from Berinsky (N.d.), who finds "little evidence of expressive responding on the question of whether Obama is a Muslim" by Republicans across four studies testing different measurement approaches. These approaches included instructions asking people not to respond expressively, a design that provided a time-based incentive for respondents to say that they did not believe Obama is Muslim; a list experiment; and data comparing explicit survey responses with implicit associations between Obama and Islam. It is impossible to prove conclusively that the responses Berinsky observes are not expressive, but the data provide no clear evidence of such a pattern.

In sum, we do not know of convincing evidence that misperceptions about highly salient facts are insincere. However, we fully acknowledge the possibility that expressive motives may influence responses to factual survey questions. Assessing the extent to which reported misperceptions are sincere (reflecting confidence in an incorrect answer) versus expressive (intentionally and knowingly reporting an incorrect answer to engage in partisan cheerleading) remains an important topic for future research. It is critical to avoid framing this issue as binary - many people who hold misperceptions answer questions incorrectly with some, 
but not total, confidence and might respond differently under other circumstances. Moreover, as with any belief measured in a survey, some misperceptions may not be strongly held, especially those that concern more obscure issues and figures.

Another measurement concern is that people may be primed by survey questions to endorse beliefs they have never held. One way to evaluate this concern is to test placebo misperceptions - fictional claims to which respondents could not have previously been exposed. For instance, a recent Chapman University survey found that $33 \%$ of Americans believe that the U.S. government is covering up the fictional "North Dakota crash" (2016). However, this question was embedded in a series of questions about prominent conspiracy theories that may have made it seem more plausible. Other fictional misperceptions have received lower levels of endorsement - for instance, Oliver and Wood (2014) find only 17\% of people claimed to have heard of their invented conspiracy theory about mind control via fluorescent bulbs and only $11 \%$ endorsed it. These are of course non-beliefs, but they do often appear to reflect related beliefs and attitudes held by the respondent. As Schuman and Presser (1980) put it, "Respondents make an educated (though wrong) guess as to what the obscure acts represent, then answer reasonably in their own terms about the constructed object." Such a response is not unreasonable given that the survey researcher has suggested by the construction of the question that the issue or claim in question is legitimate (Schwarz 2014, 35). Moreover, it is not clear what the correct placebo benchmark is to compare with reported levels of "true" beliefs — some invented misperceptions or conspiracy theories sound more plausible than others (compare, e.g., the vague and plausible-sounding "North Dakota crash" in the Chapman University survey with the more outlandish claim of mind control via fluorescent light bulbs tested in Oliver and Wood 2014). 
Any effort to address concern about non-beliefs via more traditional survey questions also faces a difficult measurement tradeoff. Closed-end questions without don't know options can overstate the proportion of people who strongly hold false or unsupported beliefs (Luskin, Sood, and Blank N.d.; Schuman and Presser 1980). Similarly, Pasek, Sood, and Krosnick (2015) suggest that many false beliefs measured in surveys are not held with high levels of confidence. An alternate approach discussed by Luskin, Sood, and Blank (N.d.) is to offer don't know options on closed-end questions or to use open-ended questions instead. These approaches would presumably reduce the prevalence of expressions of belief that respondents do not hold strongly. However, they could also understate the proportion of people who hold false beliefs by, for instance, allowing people who are misinformed to indicate uncertainty rather than belief - a particular concern when the false belief may be subject to social desirability bias. People may prefer, for instance, to state that they do not know where President Obama was born than to definitively indicate a belief that he was born outside the U.S. It is also unclear how to arbitrate between the results of different measurement approaches. The problem of misperceptions might seem less severe using open-ended questions and/or closed-end questions with don't know options, but it is not clear which set of measurements is the correct one absent some external benchmark.

Ultimately, the challenge facing the study of misperceptions - and the study of public opinion via surveys in general - is that there is no direct way to access people's "true" pre-existing beliefs absent expressive motivations, a presumption that the respondent can and will answer the questions, and/or other universal aspects of the survey response process. Indeed, the notion of a "true belief" is ill-defined given that models of survey response (e.g., Zaller 1992) suggest that 
answers are typically constructed on the spot. It is therefore not clear to us that the alternate approaches described above would represent an improvement over the status quo, though we encourage future research on these topics.

\section{The role of elites and the media in misperceptions}

Understanding the nature and origins of misperceptions requires careful examination of the actions of public figures and the media, who play a key role in disseminating false and unsupported information. However, little is known more generally about how elites exploit misinformation for strategic purposes or what effects misleading media coverage has on public opinion.

In politics, the literature on party position change and public opinion suggests that elites often play a key role in shaping voter issue positions. Carmines and Stimson (1989) and Layman et al. (2010) argue that activists help drive a process among elected officials that proceeds from the top down, prompting subsequent changes in policy preferences among party identifiers (e.g., Layman and Carsey 2002). Using ANES panel data, Goren (2005) finds that when people face a conflict between their party identification and issue positions, the resolution is more often a change in policy preference than partisanship. Similarly, Lenz (2012) argues that voters tend to adopt the policy positions of politicians they prefer rather than choosing the politician whose views best match their own - an argument that is consistent with the elite-driven model of public opinion presented in Zaller (1992).

This theoretical framework could be applied to understanding partisan and ideological belief change, which often fuels the misperceptions that are most salient and difficult to correct. Under certain circumstances, politicians may not only change the positions they express but the factual claims that they make. Indeed, 
these processes are often interrelated. Opposition to climate change mitigation is closely linked to denial of the scientific consensus, for example, though one can acknowledge global warming while, say, opposing the Kyoto Protocol (e.g., Inglis and Laffer 2008). However, this outcome was not inevitable. The parties have adopted conflicting positions on many issues in recent years, but few others center on a salient misperception. More should thus be learned about the role of elites in belief politicization on climate change and other issues. Kahan, Jamieson, Landrum, and Winneg (N.d.), for instance, show how framing Zika risks as congenial to the ideological viewpoints of either liberals or conservatives increased those group's vulnerability to false information.

Understanding the role of elites in belief polarization also has potentially important policy implications. For instance, promoting greater elite consensus on climate science might reduce misperceptions more effectively than messages directed to the public. ${ }^{26}$ Moreover, it might be more effective to counter belief politicization before it becomes entrenched at the elite level on issues like the safety of vaccines, genetically modified foods, and emergent technologies (Bolsen and Druckman 2015; Ball 2014) where misperceptions circulate widely but elite polarization is limited.

Another important macro-level factor in misperception belief is media coverage, which shapes the flow of false claims to the public both directly in its coverage and indirectly via its influence on elite behavior. One particularly important question in this area is how changes in the media environment and evolving journalistic norms affect coverage of factual disputes. Recent decades have witnessed a dramatic increase in the number and type of news programs available to media

\footnotetext{
${ }^{26}$ See also Gelpi, Feaver, and Reifler (2009, pp. 110-114) and Grieco et al. (2011) for research on how consensus affects support for the use of military force (though the consensus they consider may represent source effects).
} 
consumers. Prior (2007, ch. 4) documents how the expansion of media choice has exacerbated inequalities in political knowledge. There is good reason to suspect that it could also affect misperceptions. For instance, partisan media programs on cable television and talk radio often feature false and/or exaggerated claims about political opponents (Levendusky 2013; Jamieson and Cappella 2010). However, scholars know little about whether these programs actually increase misperceptions among consumers, many of whom are highly ideological and may already hold misperceptions. Past research has documented a correlation between partisan news consumption and misperceptions. For instance, Fox News viewership is positively associated with misperceptions about the Iraq War (Kull, Ramsay, and Lewis 2003) and global warming (Krosnick and MacInnis 2010). However, these cross-sectional correlations do not necessarily demonstrate that Fox News viewership causes misperceptions. Experimental research is needed to determine whether partisan media actually increases misperceptions. ${ }^{27}$ Another open question is whether partisan programming has indirect effects that spill over into mainstream media, which often have much larger audiences (e.g., Levendusky 2013; Jamieson and Cappella 2010). Finally, researchers should seek to identify best practices for correcting misinformation on social media - a medium that permits rapid dissemination of misinformation and presents serious challenges to fact-checkers who are not accustomed to analyzing and responding to claims in real time.

Journalistic norms also play a key role in media coverage of factual controversies. For instance, so-called "balanced" news reports that do not adequately represent the evidence in a policy or scientific debate are common and can contribute to misperceptions (e.g., Boykoff and Boykoff 2004; Boykoff 2008; Malka

\footnotetext{
${ }^{27}$ One potentially fruitful approach is to exploit the introduction of partisan news into a geographic area (e.g., Hopkins and Ladd 2014).
} 
et al. 2009; Lawrence and Schafer 2012; Dixon and Clarke 2013). ${ }^{28}$ In other cases, the content of media coverage is not just balanced but actively misleading. For example, Jerit and Barabas (2006) document a host of misleading claims about the financial status of Social Security and demonstrate experimentally that such claims cause people to become less accurate in their estimates of the program's solvency (288-291). Similarly, misleading coverage of crime (especially among local news outlets) may have contributed to widespread misperceptions that it is increasing over time (Lopez 2016a).

By contrast, other journalistic norms have the potential to help constrain elite behavior. Nyhan and Reifler (2015b) conducted a field experiment in which they reminded a large sample of state legislators of the electoral and reputational risks posed by fact-checkers. They found that these reminders reduced the likelihood that legislators would make a claim that received a negative rating from PolitiFact or whose accuracy was questioned publicly.

These findings underscore the importance of understanding the factors shaping media coverage. In a recent field experiment, for instance, Graves, Nyhan, and Reifler (2016) found that reporters provided more coverage of fact-checking when they were reminded of its status in the profession and the journalistic values it seeks to promote. By contrast, a message about audience demand for fact-checking had no significant effect. Further research is needed to determine the conditions under which media outlets are most likely to provide effective coverage of factual disputes.

Finally, it is necessary to study the actions of elites and the media to understand not only how misperceptions emerge, but which misperceptions emerge. This question is difficult to address. As discussed above, the field confronts the difficult

\footnotetext{
${ }^{28}$ Unfortunately, accurate coverage may not be enough — the public may resist accepting uncomfortable facts even when they receive substantial media coverage (Jerit and Barabas 2012).
} 
issue of an undefined denominator - there are a vast number of potential false or unsupported claims from which we only observe a highly selected sample that are made repeatedly and gain widespread adherence. Analyses of the correlates of these misperceptions are thus vulnerable to selection bias. Given that most factual beliefs are not polarized along partisan or ideological lines, understanding which ones become politicized is as important as documenting the process by which it takes place. For instance, certain types of claims may spread because they res-

onate with people's negative affect toward the opposition party (Roush N.d.) or the perceived character weaknesses of a politician (Clifford N.d.).

In trying to understand which misperceptions take hold, it is also important to consider the influence of natural cognitive limitations (e.g., Marsh, Cantor, and Brashier 2016) and the way in which elites may exploit these limitations. For instance, we instinctively process and accept information to which we are exposed and need to actively resist believing such information when it is false (Gilbert, Tafarodi, and Malone 1993). Similarly, we tend to believe that familiar information is likely to be true, which may lead us astray if false claims are widespread (Schwarz et al. 2007). Elite efforts to promote bogus claims may exploit these tendencies.

\section{Why misperceptions matter for democracy}

The research discussed above raises broader normative questions. Previous debates over democratic competence focused overwhelmingly on the potential dangers of an uninformed public. However, the prospect of widespread misperceptions calls many of this literature's findings into question and raises new, important concerns about the quality of public opinion, representation, and policy-making in democratic politics. 
We first consider how misperceptions complicate two of the most common defenses of democratic competence: heuristics and aggregation. Lupia, McCubbins, and Popkin $(2000,17)$ define heuristics as "common judgmental shortcuts that people use to draw complicated inferences from simple environmental cues." Several studies document instances of successful heuristic use. For instance, an influential study by Lupia (1994) shows that citizens can use interest group endorsements to compensate for their lack of knowledge about ballot initiatives. Of course, questions remain about the frequency of heuristic use and citizens' ability to interpret heuristics correctly (Kuklinski and Quirk 2000; Lau and Redlawsk 2001). Even when we set those issues aside, however, it is important to note that past research shows that heuristics are useful in contexts in which people likely recognize their lack of knowledge. Lupia's (1994) experiment, for instance, shows that people use endorsement heuristics to help them vote on a highly complex issue - indeed, he calls complexity the "defining characteristic" of ballot propositions (page 63). On other issues, however, many citizens hold misperceptions but believe themselves to be well-informed about the issue in question (Nyhan 2010; Kuklinski et al. 1998). This confidently misinformed group may eschew heuristics and instead base their opinions on misperceptions. To be sure, people who are weakly confident in their misperceptions (Pasek, Sood, and Krosnick 2015) may employ heuristics. However, heuristics themselves can be misleading. For example, Dancey and Sheagley (2013) show that party heuristics can mislead the most knowledgeable citizens when legislators vote in counter-stereotypical ways. In short, while heuristics may help overcome ignorance, they are less clearly helpful for assisting people in overcoming misperceptions.

Another defense of democratic competence focuses on the aggregation of individual- 
level preferences into collective public opinion. On this account, the process of statistical aggregation cancels out random errors in individual-level preferences, creating a more sensible indicator of public opinion at the macro level (Page and Shapiro 1992). As with heuristics, scholars continue to debate the usefulness of aggregation for overcoming ignorance (e.g., Caplan 2007; Kuklinski and Quirk 2000). However, further grounds exist for skepticism. Perhaps the most obvious concern is the possibility of systematic misperceptions in the mass public, which violate the random error assumption underlying models of collective rationality (see, e.g., Page and Shapiro 1992, 29). For example, Americans tend to systematically overestimate the number of immigrants in the country (Hopkins, Sides, and Citrin N.d.) and underestimate the share of federal income taxes coming from the top one percent of earners (Flynn 2016). If systematic misperceptions like these are common, aggregation will compound individual-level errors in public opinion rather than eliminating them.

Beyond public opinion, misperceptions could also distort important aspects of representation. First, though elites may try to persuade uninformed constituents to support their position, they may be more reluctant to listen to or engage with citizens whom they perceive to be misinformed (e.g., Honda 2009), reducing both legislative responsiveness and constituent exposure to corrective information. Misperceptions among politicians themselves about constituent opinion could also undermine policy responsiveness (e.g., Miller and Stokes 1963). Indeed, Broockman and Skovron (2015) show that candidates for state legislative office are widely misinformed about public opinion in their districts: the typical candidate substantially underestimates district support for universal health care and same-sex marriage.

Finally, in some cases, misperceptions can distort policy debates and even af- 
fect the content of legislation itself. As discussed above, the "death panel" misperception skewed the debate over the Affordable Care Act not only by distorting public beliefs but by reducing public and media attention to other fact-based criticisms of the legislation. On other issues, politicians and their staff may hold misperceptions that affect their policy positions. For instance, Bolsen, Druckman, and Cook (2015) provide evidence of misperceptions among congressional staffers about global warming. Of course, the existence of a misperception among citizens or policymakers does not necessarily means that it affects policy outcomes. Future research should therefore seek to trace the effect of prominent misperceptions on policy debates using archival or historical data (see, e.g., Nyhan 2010).

\section{Conclusion}

The evidence presented above suggests that misperceptions are widespread and that elites and the media play a key role in promoting these false and unsupported beliefs. In many cases, misperceptions appear to distort people's opinions and behavior. Even when they do not have such effects, these misperceptions can still have pernicious consequences for the factual basis of both political debate and public policy itself.

Nonetheless, difficult research questions remain. Three questions stand out

as particularly important. First, scholars should seek to better understand the conditions under which directional motivations will predominate when assessing political information. To what extent will people respond to facts that contradict their prior attitudes or predispositions? Conditions such as polarization, party cues, and others discussed above lead to misperceptions about some (but certainly not all) political facts. Clarifying the scope of these conditions is critical to under- 
stand when misperceptions are likely to develop. Second, how can we best measure misperceptions to discourage expressive responding while avoiding underreporting and minimizing social desirability concerns? Finally, the study of misperceptions must reduce its near-exclusive focus on the mass public and consider political elites and the media, who help determine which beliefs become politicized and when and how such a process takes place.

If the conclusions reached so far are correct, however, the threat of misperceptions to democracy cannot be avoided, especially in the highly polarized world of contemporary American politics. Facts are always at least potentially vulnerable to directional motivated reasoning, especially when they are politicized by elites. The polarization that our politics must confront is thus not just over issues and public policy, but over reality itself.

\section{References}

Arceneaux, Kevin. 2012. "Cognitive biases and the strength of political arguments." American Journal of Political Science 56 (2): 271-285.

Aronow, Peter M., and Benjamin T. Miller. 2016. "Policy misperceptions and support for gun control legislation." Lancet 387 (10015): 223-223.

Bakshy, Eytan, Solomon Messing, and Lada A. Adamic. 2015. "Exposure to ideologically diverse news and opinion on Facebook." Science 348 (6239): 1130-1132.

Ball, Molly. 2014. "Want to Know If Your Food Is Genetically Modified?" The Atlantic, May 14, 2014. Downloaded June 13, 2016 from http://www.theatlantic.com/politics/archive/2014/05/

want-to-know-if-your-food-is-genetically-modified/370812/. 
Barberá, Pablo, John T. Jost, Jonathan Nagler, Joshua A. Tucker, and Richard Bonneau. 2015. "Tweeting From Left to Right Is Online Political Communication More Than an Echo Chamber?" Psychological Science 26 (10): 1531-1542.

Bartels, Larry M. 2002. "Beyond the running tally: Partisan bias in political perceptions." Political Behavior 24 (2): 117-150.

Berinsky, Adam J. 2009. In time of war: Understanding American public opinion from World War II to Iraq. University of Chicago Press.

Berinsky, Adam J. 2015. "Rumors and Health Care Reform: Experiments in Political Misinformation." British Journal of Political Science.

Berinsky, Adam J. N.d. "Telling the Truth about Believing the Lies?" Unpublished manuscript.

Bode, Leticia, and Emily K Vraga. 2015. "In related news, that was wrong: The correction of misinformation through related stories functionality in social media." Journal of Communication 65 (4): 619-638.

Bollinger, Bryan, and Kenneth Gillingham. 2012. "Peer effects in the diffusion of solar photovoltaic panels." Marketing Science 31 (6): 900-912.

Bolsen, Toby, and James N Druckman. 2015. "Counteracting the politicization of science." Journal of Communication 65 (5): 745-769.

Bolsen, Toby, James N. Druckman, and Fay Lomax Cook. 2014. "The Influence of Partisan Motivated Reasoning on Public Opinion." Political Behavior 36 (2): $235-262$. 
Bolsen, Toby, James N. Druckman, and Fay Lomax Cook. 2015. "Citizens', Scientists', and Policy Advisors' Beliefs about Global Warming." Annals of the American Academy of Arts and Sciences 658 (March): 271-295.

Bond, Robert M., Christopher J. Fariss, Jason J. Jones, Adam DI Kramer, Cameron Marlow, Jaime E. Settle, and James H. Fowler. 2012. "A 61million-person experiment in social influence and political mobilization." Nature 489 (7415): 295-298.

Boykoff, Maxwell T. 2008. "Lost in translation? United States television news coverage of anthropogenic climate change, 1995-2004." Climatic Change 86 (12): $1-11$.

Boykoff, Maxwell T., and Jules M. Boykoff. 2004. "Balance as bias: Global warming and the US prestige press." Global environmental change 14 (2): 125-136.

Broockman, David, and Christopher Skovron. 2015. "What Politicians Believe About Their Constituents: Asymmetric Misperceptions and Prospects for Constituency Control." Unpublished manuscript.

Bullock, John. 2007. "Experiments on partisanship and public opinion: Party cues, false beliefs, and Bayesian updating." Ph.D. dissertation, Stanford University.

Bullock, John G. 2011. "Elite Influence on Public Opinion in an Informed Electorate." American Political Science Review 105 (3): 496-515.

Bullock, John G., Alan S. Gerber, Seth J. Hill, and Gregory A. Huber. 2015. "Partisan Bias in Factual Beliefs about Politics." Quarterly Journal of Political Science 10: 519-578. 
Bullock, John G., Donald P. Green, and Shang E. Ha. 2010. "Yes, but what's the mechanism?(don't expect an easy answer)." Journal of personality and social psychology 98 (4): 550-558.

Caplan, Bryan. 2007. The Myth of the Rational Voter: Why Democracies Choose Bad Policies. Princeton, NJ: Princeton University Press.

Carmines, Edward G., and James A. Stimson. 1989. Issue evolution: Race and the transformation of American politics. Princeton University Press.

Chapman University Survey of American Fears. 2016. "What Aren't They Telling Us?" October 11, 2016. Downloaded October 26, 2016 from https://blogs . chapman.edu/wilkinson/2016/10/11/what-arent-they-telling-us/.

Clifford, Scott. N.d. "Confirming the Worst: Candidate Rumors and Character Trait Perceptions." Unpublished manuscript.

Cobb, Michael D., Brendan Nyhan, and Jason Reifler. 2013. "Beliefs Don't Always Persevere: How Political Figures Are Punished When Positive Information about Them Is Discredited." Political Psychology 34 (3): 307-326.

Cohen, Geoffrey L., Joshua Aronson, and Claude M. Steele. 2000. "When beliefs yield to evidence: Reducing biased evaluation by affirming the self." Personality and Social Psychology Bulletin 26 (9): 1151-1164.

Converse, Phillip E. 1964. "The Nature of Belief Systems in Mass Publics." In Ideology and Discontent, ed. David E. Apter. New York: Free Press.

Correll, Joshua, and Mark P. Spencer, Steven J.and Zanna. 2004. "An affirmed self and an open mind: Self-affirmation and sensitivity to argument strength." Journal of Experimental Social Psychology 40 (3): 350-356. 
Dancey, Logan, and Geoffrey Sheagley. 2013. "Heuristics Behaving Badly: Party Cues and Voter Knowledge." American Journal of Political Science 57 (2): 312325.

Delli Carpini, Michael X., and Scott Keeter. 1996. What Americans Know about Politics and Why It Matters. New Haven: Yale University Press.

DiFonzo, Nicholas, and Prashant Bordia. 2006. Rumor Psychology: Social and Organizational Approaches. American Psychological Association.

Dixon, Graham N., and Christopher E. Clarke. 2013. "Heightening uncertainty around certain science media coverage, false balance, and the autism-vaccine controversy." Science Communication 35 (3): 358-382.

Druckman, James N. 2012. "The politics of motivation." Critical Review 24 (2): 199-216.

Druckman, James N., Erik Peterson, and Rune Slothuus. 2013. "How Elite Partisan Polarization Affects Public Opinion Formation." American Political Science Review 107 (1): 57-79.

Duelfer, Charles. 2004. Comprehensive Report of the Special Advisor to the DCI on Iraq's WMD. Central Intelligence Agency.

Entine, Jon. 2015. "AAAS Scientists: Consensus on GMO Safety Firmer Than For Human-Induced Climate Change." Huffington Post, January 29, 2015. Downloaded July 11, 2016 from http://www.huffingtonpost.com/jon-entine/ post_8915_b_6572130.html.

Federal Bureau of Investigation. 2015. "Crime in the United States." Downloaded 
from https://ucr.fbi.gov/crime-in-the-u.s/2015/crime-in-the-u.s. -2015/tables/table-1 on October 24, 2016.

Flaxman, Seth R., Sharad Goel, and Justin M. Rao. 2016. "Filter Bubbles, Echo Chambers, and Online News Consumption." Public Opinion Quarterly 80 (Special issue): 298-320.

Flynn, D.J. 2016. "The Scope and Correlates of Political Misperceptions in the Mass Public." Paper delivered at the Annual Meeting of the American Political Science Association, Philadelphia, September.

Freed, Gary L., Sarah J. Clark, Amy T. Butchart, Dianne C. Singer, and Matthew M. Davis. 2010. "Parental vaccine safety concerns in 2009." Pediatrics 125 (4): $654-659$.

Fridkin, Kim, Patrick J. Kenney, and Amanda Wintersieck. 2015. "Liar, Liar, Pants on Fire: How Fact-Checking Influences Citizens' Reactions to Negative Advertising." Political Communication 32 (1): 127-151.

Gaines, Brian J., James H. Kuklinski, Paul J. Quirk, Buddy Peyton, and Jay Verkuilen. 2007. "Same facts, different interpretations: Partisan motivation and opinion on Iraq." Journal of Politics 69 (4): 957-974.

Garrett, R. Kelly, Erik C. Nisbet, and Emily K. Lynch. 2013. "Undermining the corrective effects of media-based political fact checking? The role of contextual cues and naïve theory." Journal of Communication 63 (4): 617-637.

Gelman, Andrew. 2014. "Thinking of doing a list experiment? Here's a list of reasons why you should think again." April 23, 2014. Down- 
loaded October 27, 2016 from http://andrewgelman.com/2014/04/23/ thinking-list-experiment-heres-list-reasons-think/.

Gelpi, Christopher, Peter D. Feaver, and Jason Reifler. 2009. Paying the human costs of war: American public opinion and casualties in military conflicts. Princeton University Press.

Gentzkow, Matthew A., and Jesse M. Shapiro. 2004. "Media, Education and AntiAmericanism in the Muslim World." Journal of Economic Perspectives 18 (3): $117-133$.

Gentzkow, Matthew, and Jesse M Shapiro. 2011. "Ideological Segregation Online and Offline." Quarterly Journal of Economics 126 (4): 1799-1839.

Gerber, Alan S., Donald P. Green, and Christopher W. Larimer. 2008. "Social pressure and voter turnout: Evidence from a large-scale field experiment." American Political Science Review 102 (01): 33-48.

Gerber, Alan S., and Gregory A. Huber. 2009. "Partisanship and Economic Behavior: Do Partisan Differences in Economic Forecasts Predict Real Economic Behavior?" American Political Science Review 103 (3): 407-426.

Gerber, Alan S., and Todd Rogers. 2009. "Descriptive social norms and motivation to vote: everybody's voting and so should you." Journal of Politics 71 (01): 178191.

Gidda, Mirren. 2014. "Fear and Rumors Fueling the Spread of Ebola." Time, August 12, 2014. Downloaded October 27, 2016 from http://time.com/3092855/ ebola-fear-rumors/. 
Gilbert, Daniel T., Romin W. Tafarodi, and Patrick S. Malone. 1993. "You can't not believe everything you read." Journal of personality and social psychology 65 (2): $221-233$.

Gollust, Sarah E., Paula M. Lantz, and Peter A. Ubel. 2009. "The polarizing effect of news media messages about the social determinants of health." American Journal of Public Health 99 (12): 2160.

Goren, Paul. 2005. "Party identification and core political values." American Journal of Political Science 49 (4): 881-896.

Graves, Lucas, Brendan Nyhan, and Jason Reifler. 2016. "Understanding Innovations in Journalistic Practice: A Field Experiment Examining Motivations for Fact-Checking." Journal of Communication 66 (1): 102-138.

Green, Donald, Bradley Palmquist, and Eric Schickler. 2004. Partisan Hearts and Minds: Political Parties and the Social Identities of Voters. New Haven, CT: Yale University Press.

Grieco, Joseph M., Christopher Gelpi, Jason Reifler, and Peter D. Feaver. 2011. "Let's Get a Second Opinion: International Institutions and American Public Support for War." International Studies Quarterly 55 (2): 563-583.

Groenendyk, Eric. 2013. Competing Motives in the Partisan Mind: How Loyalty and Responsiveness Shape Party Identification and Democracy. New York: Oxford University Press.

Grossmann, Matt, and David A. Hopkins. 2016. Asymmetric Politics: Ideological Republicans and Group Interest Democrats. Oxford University Press. 
Guess, Andrew, and Alexander Coppock. N.d. "The Exception, Not the Rule? The Rarely Polarizing Effect of Challenging Information." Unpublished manuscript.

Guess, Andrew M. N.d. "Media Choice and Moderation: Evidence from Online Tracking Data." Unpublished manuscript.

Hastorf, Albert H., and Hadley Cantril. 1954. "They saw a game: A case study." Journal of Abnormal and Social Psychology 49 (1): 129-134.

Hill, Seth J. N.d. "Learning Together Slowly: Bayesian Learning About Political Facts." Unpublished manuscript.

Hochschild, Jennifer L., and Katherine Levine Einstein. 2015. Do Facts Matter? Information and Misinformation in American Politics. Norman, OK: University of Oklahoma Press.

Honda, Michael. 2009. "Misinformation Makes Town Hall Meetings Tough." The Mercury News, September 8, 2009.

Hopkins, Daniel J, John Sides, and Jack Citrin. N.d. "The Muted Consequences of Correct Information About Immigration." Unpublished manuscript.

Hopkins, Daniel J., and Jonathan M. Ladd. 2014. "The Consequences of Broader Media Choice: Evidence from the Expansion of Fox News." Quarterly Journal of Political Science 9 (1): 115-135.

Howell, William G., and Martin R. West. 2009. "Educating the Public." Education Next 9 (3): 41-47.

Inglis, Bob, and Arthur B. Laffer. 2008. "An Emissions Plan Conservatives Could Warm To." New York Times, December 27, 2008. 
Ipsos MORI. 2016. "The Perils of Perception and the EU: Public misperceptions about the EU and how it affects life in the UK." Poll conducted May 27-30, 2016. Available at https://www.ipsos-mori.com/researchpublications/ researcharchive/3742/The-Perils-of-Perception-and-the-EU. aspx.

Iyengar, Shanto, Gaurav Sood, and Yphtach Lelkes. 2012. "Affect, Not Ideology: A Social Identity Perspective on Polarization." Public Opinion Quarterly 76 (3): 405-431.

Jamieson, Kathleen Hall, and Joseph N. Cappella. 2010. Echo Chamber: Rush Limbaugh and the Conservative Media Establishment. Oxford University Press.

Jerit, Jennifer, and Jason Barabas. 2006. "Bankrupt Rhetoric: How Misleading Information Affects Knowledge about Social Security." Public Opinion Quarterly 70 (3): 278-303.

Jerit, Jennifer, and Jason Barabas. 2012. "Partisan perceptual bias and the information environment." Journal of Politics 74 (3): 672-684.

Jerit, Jennifer, Jason Barabas, and Scott Clifford. 2013. "Comparing contemporaneous laboratory and field experiments on media effects." Public Opinion Quarterly 77 (1): 256-282.

Jost, John T., Jack Glaser, Arie W. Kruglanski, and Frank J. Sulloway. 2003. "Political Conservatism as Motivated Social Cognition." Psychological Bulletin 129 (3): 339-375.

Kahan, Dan. 2015a. "Against "consensus messaging"..." Cultural Cognition blog, June 10, 2015. Downloaded October 31, 2016 from http://www . 
culturalcognition.net/blog/2015/6/10/against-consensus-messaging. html.

Kahan, Dan M. 2015b. "Climate-Science Communication and the Measurement Problem." Advances in Political Psychology 36 (S1): 1-43.

Kahan, Dan M., Asheley Landrum, Katie Carpenter, Laura Helft, and Kathleen Hall Jamieson. N.d. "Science Curiosity and Political Information Processing." Forthcoming, Advances in Political Psychology.

Kahan, Dan M., Erica Cantrell Dawson, Ellen Peters, and Paul Slovic. N.d. "Motivated Numeracy and Enlightened Self-Government." Unpublished manuscript.

Kahan, Dan M., Kathleen Hall Jamieson, Asheley R Landrum, and Kenneth Winneg. N.d. "Culturally Antagonistic Memes and the Zika Virus: An Experimental Test." Forthcoming, Journal of Risk Research.

Kam, Cindy D. 2005. "Who Toes the Party Line? Cues, Values, and Individual Differences." Political Behavior 27 (2): 163-182.

URL: http://dx.doi.org/10.1007/s11109-005-1764-y

Kam, Cindy D., and Donald R. Kinder. 2012. "Ethnocentrism as a short-term force in the 2008 American presidential election." American Journal of Political Science 56 (2): 326-340.

Kast, Felipe, Stephan Meier, and Dina Pomeranz. 2012. "Under-savers anonymous: Evidence on self-help groups and peer pressure as a savings commitment device." Unpublished manuscript.

Kim, Jin Woo. N.d. "The Force of the Better Evidence in Political Belief Updating." Unpublished manuscript. 
Kosloff, Spee, Jeff Greenberg, Toni Schmader, Mark Dechesne, and David Weise. 2010. "Smearing the opposition: Implicit and explicit stigmatization of the 2008 US Presidential candidates and the current US President." Journal of Experimental Psychology: General 139 (3): 383-398.

Kramon, Eric, and Keith R. Weghorst. 2012. "Measuring Sensitive Attitudes in Developing Countries: Lessons from Implementing the List Experiment." The Political Methodologist 3 (2): 14-24.

Krosnick, Jon A., and Bo MacInnis. 2010. "Frequent Viewers of Fox News Are Less Likely to Accept Scientists' Views of Global Warming." Report for The Woods Institute for the Environment. Downloaded July 20, 2014 from http: //woods.stanford.edu/docs/surveys/Global-Warming-Fox-News.pdf.

Kuklinski, James H., Michael D. Cobb, and Martin Gilens. 1997. "Racial Attitudes and the "New South"." Journal of Politics 59 (2): 323-349.

Kuklinski, James H., and Paul J. Quirk. 2000. "Reconsidering the Rational Public: Cognition, Heuristics, and Mass Opinion." In Elements of Reason: Understanding and Expanding the Limits of Political Rationality, ed. Arthur Lupia, Mathew D. McCubbins, and Samuel L. Popkin. London: Cambridge University Press.

Kuklinski, James H., Paul J. Quirk, David W. Schwieder, and Robert F. Rich. 1998. "Just the Facts, Ma'am: Political Facts and Public Opinion." Annals of the American Academy of Political and Social Science 560 (November): 143-154.

Kuklinski, James H., Paul J. Quirk, Jennifer Jerit, David Schwieder, and Robert F. 
Rich. 2000. "Misinformation and the Currency of Democratic Citizenship." Journal of Politics 62 (3): 790-816.

Kull, Steven, Clay Ramsay, and Evan Lewis. 2003. "Misperceptions, the Media, and the Iraq War." Political Science Quarterly 118 (4): 569-598.

Kunda, Ziva. 1990. "The case for motivated reasoning." Psychological bulletin 108 (3): 480-498.

Ladd, Jonathan McDonald, and Gabriel S. Lenz. 2008. "Reassessing the role of anxiety in vote choice." Political Psychology 29 (2): 275-296.

Ladd, Jonathan McDonald, and Gabriel S. Lenz. 2011. "Does Anxiety Improve Voters' Decision Making?" Political Psychology 32 (2): 347-361.

Lau, Richard R., and David P. Redlawsk. 2001. "Advantages and disadvantages of cognitive heuristics in political decision making." American Journal of Political Science 45 (4): 951-971.

Lauderdale, Benjamin E. 2016. "Partisan Disagreements Arising from Rationalization of Common Information." Political Science Research and Methods 4 (3): 477-492.

Lavine, Howard G., Christopher D. Johnston, and Marco R. Steenbergen. 2012. The Ambivalent Partisan: How Critical Loyalty Promotes Democracy. New York: Cambridge University Press.

Lawrence, Regina G., and Matthew L. Schafer. 2012. "Debunking Sarah Palin: Mainstream news coverage of 'death panels'." Journalism 13 (6): 766-782. 
Layman, Geoffrey C, and Thomas M Carsey. 2002. "Party polarization and 'conflict extension' in the American electorate." American Journal of Political Science 46 (4): 786-802.

Layman, Geoffrey C., Thomas M. Carsey, John C. Green, Richard Herrera, and Rosalynn Cooperman. 2010. "Activists and Conflict Extension in American Party Politics." American Political Science Review 104 (2): 324-346.

Lenz, Gabriel S. 2012. Follow the leader? How voters respond to politicians' performance and policies. Chicago, IL: University of Chicago Press.

Leonard, Kimberly. 2015. "Is the 'Death Panel' Debate Dead?" U.S. News 86 World Report, July 9, 2015.

Levendusky, Matthew. 2013. How Partisan Media Polarize America. University of Chicago Press.

Levendusky, Matthew S. 2010. "Clearer Cues, More Consistent Voters: A Benefit of Elite Polarization." Political Behavior 32 (1): 111-131.

Lewandowsky, Stephan, Gilles E Gignac, and Samuel Vaughan. 2013. "The pivotal role of perceived scientific consensus in acceptance of science." Nature Climate Change 3 (4): 399-404.

Lodge, Milton, and Charles S. Taber. 2013. The Rationalizing Voter. Cambridge University Press.

Lopez, German. 2016a. "Americans don't know crime has plummeted. In fact, they think it's gone up." Vox, October 10, 2016. Downloaded October 27, 2016 from http://www.vox.com/policy-and-politics/2016/10/10/ 13226264/us-crime-rate-poll. 
Lopez, German. 2016b. "Trump: murder is at a 45-year high. Actual statistics: that's not remotely true." Vox, October 21, 2016. Downloaded from http://www . vox.com/2016/10/12/13255466/trump-murder-rate on October 24,2016 .

Lupia, Arthur. 1994. "Shortcuts Versus Encyclopedias: Information and Voting Behavior in California Insurance Reform Elections." American Political Science Review 88 (1): 63-76.

Lupia, Arthur. 2006. "How elitism undermines the study of voter competence." Critical Review 18 (1-3): 217-232.

Lupia, Arthur, and Mathew D. McCubbins. 1998. The Democratic Dilemma: Can Citizens Learn What They Need to Know? New York: Cambridge University Press.

Lupia, Arthur, Mathew D. McCubbins, and Samuel L. Popkin. 2000. "Beyond Rationality: Reason and the Study of Politics." In Elements of Reason: Understanding and Expanding the Limits of Political Rationality, ed. Arthur Lupia, Mathew D. McCubbins, and Samuel L. Popkin. London: Cambridge University Press.

Luskin, Robert C., Gaurav Sood, and Joshua Blank. N.d. "The Waters of Casablanca: Political Misinformation (and Knowledge and Ignorance)." Unpublished manuscript.

Malka, Ariel, Jon A. Krosnick, Matthew Debell, Josh Pasek, and Daniel Schneider. 2009. "Featuring Skeptics in News Media Stories About Global Warming 
Reduces Public Beliefs in the Seriousness of Global Warming." Woods Institute for the Environment, Stanford University.

Marcus, George E., W. Russell Neuman, and Michael MacKuen. 2000. Affective intelligence and political judgment. University of Chicago Press.

Marsh, Elizabeth J., Allison D. Cantor, and Nadia M. Brashier. 2016. "Believing that Humans Swallow Spiders in Their Sleep: False Beliefs as Side Effects of the Processes that Support Accurate Knowledge." Psychology of Learning and Motivation 64: 93-132.

McCright, Aaron M., and Riley E. Dunlap. 2011. "The politicization of climate change and polarization in the American public's views of global warming, 20012010." Sociological Quarterly 52 (2): 155-194.

Meer, Jonathan. 2011. "Brother, can you spare a dime? Peer pressure in charitable solicitation." Journal of Public Economics 95 (7): 926-941.

Miller, Warren E., and Donald W. Stokes. 1963. "Constituency Influence in Congress." American Political Science Review 57: 45-56.

Mullinix, Kevin J. 2016. "Partisanship and Preference Formation: Competing Motivations, Elite Polarization, and Issue Importance." Political Behavior 38 (2): $383-411$.

Nyhan, Brendan. 2010. "Why the 'death panel' myth won't die: Misinformation in the health care reform debate." The Forum 8 (1).

Nyhan, Brendan. 2011. "The limited effects of testimony on political persuasion." Public Choice 148 (3-4): 283-312. 
Nyhan, Brendan. 2012. "New Surveys Show the Persistence of Misperceptions." Huffington Post Pollster, July 30, 2012. Downloaded July 19, 2014 from http://www.huffingtonpost.com/brendan-nyhan/ new-surveys-show-the-pers_b_1718794.html.

Nyhan, Brendan. 2014. "Can We Have a Fact-Based Conversation About End-of-Life Planning?" New York Times, September 10, 2014. Downloaded June 13, 2016 from http://www.nytimes.com/2014/09/11/upshot/ can-we-have-a-fact-based-conversation-about-end-of-life-planning . html.

Nyhan, Brendan, and Jason Reifler. 2010. "When Corrections Fail: The persistence of political misperceptions." Political Behavior 32 (2): 303-330.

Nyhan, Brendan, and Jason Reifler. 2012. "Misinformation and Fact-checking: Research Findings from Social Science." New America Foundation Media Policy Initiative Research Paper.

Nyhan, Brendan, and Jason Reifler. 2013. "Which Corrections Work? Research results and practice recommendations." New America Foundation Media Policy Initiative Research Paper.

Nyhan, Brendan, and Jason Reifler. 2015a. "Displacing misinformation about events: An experimental test of causal corrections." Journal of Experimental Political Science 2 (1): 81-93.

Nyhan, Brendan, and Jason Reifler. 2015b. "The Effect of Fact-Checking on Elites: A Field Experiment on US State Legislators." American Journal of Political Science 59 (3): 628-640. 
Nyhan, Brendan, and Jason Reifler. N.d.a. "Do People Actually Learn From Fact-Checking? Evidence from a longitudinal study during the 2014 campaign." Unpublished manuscript.

Nyhan, Brendan, and Jason Reifler. N.d.b. "The role of information deficits and identity threat in the prevalence of misperceptions." Unpublished manuscript.

Nyhan, Brendan, Jason Reifler, and Peter A. Ubel. 2013. "The hazards of correcting myths about health care reform." Medical Care 51 (2): 127-132.

O’Keefe, Daniel J. 2002. Persuasion. 2nd ed. Thousand Oaks, CA: Sage Publications.

Oliver, J. Eric, and Thomas J. Wood. 2014. "Conspiracy Theories and the Paranoid Style (s) of Mass Opinion." American Journal of Political Science.

Page, Benjamin I., and Robert Y. Shapiro. 1992. The rational public: Fifty years of trends in Americans' policy preferences. University of Chicago Press.

Paluck, Elizabeth Levy. 2011. "Peer pressure against prejudice: A high school field experiment examining social network change." Journal of Experimental Social Psychology 47 (2): 350-358.

Paluck, Elizabeth Levy, and Hana Shepherd. 2012. "The salience of social referents: A field experiment on collective norms and harassment behavior in a school social network." Journal of Personality and Social Psychology 103 (6): 899-915.

Pasek, Josh, Gaurav Sood, and Jon A. Krosnick. 2015. "Misinformed About the Affordable Care Act? Leveraging Certainty to Assess the Prevalence of Misperceptions." Journal of Communication 65 (4): 660-673. 
Pear, Robert. 2015. "New Medicare Rule Authorizes 'End-of-Life' Consultations." New York Times, October 30, 2015.

Petersen, Michael Bang. 2015. "Evolutionary Political Psychology: On the Origin and Structure of Heuristics and Biases in Politics." Political Psychology 36 (S1): $45-78$.

Petersen, Michael Bang, Martin Skov, Søren Serritzlew, and Thomas Ramsøy. 2013. "Motivated Reasoning and Political Parties: Evidence for Increased Processing in the Face of Party Cues." Political Behavior 35 (4): 831-854.

Polikoff, Morgan. 2015. "The more people know about Common Core, the less they know about Common Core." September 8, 2015. Downloaded July 11, 2016 from https://morganpolikoff.com/2015/09/08/ the-more-people-know-about-common-core-the-less-they-know-about-common-core/.

Prasad, Monica, Andrew J Perrin, Kieran Bezila, Steve G Hoffman, Kate Kindleberger, Kim Manturuk, and Ashleigh Smith Powers. 2009. "'There must be a reason': Osama, Saddam, and inferred justification." Sociological Inquiry 79 (2): $142-162$.

Prior, Markus. 2007. Post-broadcast democracy: How media choice increases inequality in political involvement and polarizes elections. Cambridge University Press.

Prior, Markus, Gaurav Sood, and Kabir Khanna. 2015. "You Cannot be Serious: The Impact of Accuracy Incentives on Partisan Bias in Reports of Economic Perceptions." Quarterly Journal of Political Science 10 (4): 489-518. 
Ramsay, Clay, Steven Kull, Evan Lewis, and Stefan Subias. 2010. "Misinformation and the 2010 election: A study of the US electorate." Worldpublicopinion.org, December 2010. Downloaded July 18, 2014 from http://www. worldpublicopinion.org/pipa/pdf/dec10/Misinformation_ Dec10_rpt.pdf.

Redlawsk, David P. 2002. "Hot Cognition or Cool Consideration? Testing the Effects of Motivated Reasoning on Political Decision Making." Journal of Politics 64 (4): 1021-1044.

Redlawsk, David P., Andrew J.W. Civettini, and Karen M. Emmerson. 2010. "The affective tipping point: Do motivated reasoners ever 'get it'?" Political Psychology 31 (4): 563-593.

Ross, Lee, Mark R. Lepper, and Michael Hubbard. 1975. "Perseverance in selfperception and social perception: Biased attributional processes in the debriefing paradigm." Journal of Personality and Social Psychology 32 (5): 880-892.

Roush, Carolyn E. N.d. "Believing the Worst: Out-Party Hostility and Receptiveness to Political Misinformation." Unpublished manuscript.

Schaffner, Brian F., and Cameron Roche. N.d. "Misinformation and Motivated Reasoning: Responses to Economic News in a Politicized Environment." Forthcoming, Public Opinion Quarterly.

Schuman, Howard, and Stanley Presser. 1980. "Public opinion and public ignorance: The fine line between attitudes and nonattitudes." American Journal of Sociology 85 (5): 1214-1225. 
Schwarz, Norbert. 2014. Cognition and communication: Judgmental biases, research methods, and the logic of conversation. Psychology Press.

Schwarz, Norbert, Lawrence J. Sanna, Ian Skurnik, and Carolyn Yoon. 2007. "Metacognitive experiences and the intricacies of setting people straight: Implications for debiasing and public information campaigns." Advances in experimental social psychology 39: 127-161.

Sides, John. 2016. "Stories or Science? Facts, Frames, and Policy Attitudes." American Politics Research 44 (3): 387-414.

Sides, John, and Jack Citrin. 2007. "European Opinion about Immigration: The Role of Identities, Interests and Information." British Journal of Political Science $37(3): 477-504$.

Sinclair, Betsy. 2012. The Social Citizen: Peer Networks and Political Behavior. Chicago: University of Chicago Press.

Slothuus, Rune, and Claes H. de Vreese. 2010. "Political Parties, Motivated Reasoning, and Issue Framing Effects." Journal of Politics 72 (3): 630-645.

Steele, Claude M. 1988. "The psychology of self-affirmation: Sustaining the integrity of the self." Advances in experimental social psychology 21: 261-302.

Stroud, Natalie Jomini. 2008. "Media use and political predispositions: Revisiting the concept of selective exposure." Political Behavior 30 (3): 341-366.

Sunstein, Cass R., and Adrian Vermeule. 2009. "Conspiracy theories: Causes and cures." Journal of Political Philosophy 17 (2): 202-227. 
Taber, Charles S., and Milton Lodge. 2006. "Motivated Skepticism in the Evaluation of Political Beliefs." American Journal of Political Science 50 (3): 755-769.

Thorson, Emily. 2015a. "Belief echoes: The persistent effects of corrected misinformation." Political Communication.

Thorson, Emily. 2015b. "Identifying and Correcting Policy Misperceptions." American Press Institute research report.

Uscinski, Joseph E., Casey Klofstad, and Matthew D. Atkinson. 2016. "What Drives Conspiratorial Beliefs? The Role of Informational Cues and Predispositions." Political Research Quarterly 69 (1): 57-71.

Uscinski, Joseph E., and Joseph M. Parent. 2014. American conspiracy theories. Oxford University Press.

Weeks, Brian E. 2015. "Emotions, partisanship, and misperceptions: How anger and anxiety moderate the effect of partisan bias on susceptibility to political misinformation." Journal of Communication 65 (4): 699-719.

Weiner, Rachel, and Scott Clement. 2012. "Why Obama gets less blame than Bush for high gas prices." Washington Post, March 30, 2012. Downloaded October 27, 2016 from https://web.archive.org/web/ 20120528071226/http://www . washingtonpost.com/blogs/the-fix/post/ a-double-standard-on-gas-prices/2012/03/29/gIQAVMHRjS_blog.html.

Wilkes, A.L., and M. Leatherbarrow. 1988. "Editing episodic memory following the identification of error." Quarterly Journal of Experimental Psychology 40 (2): $361-387$. 
Wood, Thomas, and Ethan Porter. N.d. "The elusive backfire effect: mass attitudes' steadfast factual adherence." Unpublished manuscript.

Zaller, John. 1992. The Nature and Origins of Mass Opinion. Cambridge University Press. 